\title{
Effect of IFKhAN-92 inhibitor on scale removal during sulfuric acid pickling of steel
}

\author{
Ya. G. Avdeev, ${ }^{1}$ I. G. Gorichev ${ }^{2}$ and A. Yu. Luchkin ${ }^{2}$ \\ ${ }^{1}$ A. N. Frumkin Institute of Physical Chemistry and Electrochemistry, Russian Academy \\ of Sciences, Leninskii pr. 31, Moscow, 119071 Russian Federation \\ E-mail:avdeev@kspu.kaluga.ru \\ ${ }^{2}$ Moscow State Pedagogical University, ul. Malaya Pirogovskaya 1, bldg. 1, \\ Moscow, 119882 Russian Federation \\ E-mail:skay54@yandex.ru
}

\begin{abstract}
An integrated study of the effect of IFKhAN-92 on steel pickling in sulfuric acid solutions has been carried out. The inhibitor studied significantly reduces the corrosion rate of the metal but does not hinder the scale removal. It has been shown that the electrochemical component of the scale pickling process is described by Erofeev's equation of heterogeneous kinetics.
\end{abstract}

Key words: acid corrosion, corrosion inhibitors, acidic steel pickling, scale removal, iron oxides.

Received: August 2, 2012.

doi: $\underline{10.17675 / 2305-6894-2012-1-1-026-037}$

\section{Introduction}

Steel pickling in solutions of mineral acids is the most popular method for the removal of mill scale and high-temperature scale from steel surfaces. It is widely used in smelting industry and in machine-building industry [1]. Scale formed on carbon steels consists of a number of oxide layers whose compositions are determined by the scale formation conditions [2]. A wustite layer $(\mathrm{FeO})$ is adjacent to the metal; the intermediate layer consists of magnetite $\left(\mathrm{Fe}_{3} \mathrm{O}_{4}\right)$, while the external layer consists of hematite $\left(\mathrm{Fe}_{2} \mathrm{O}_{3}\right)$. Scale formed at $\mathrm{t} \geq 575^{\circ} \mathrm{C}$ contains all the three oxides, whereas scale formed at lower temperatures consists of $\mathrm{Fe}_{3} \mathrm{O}_{4}$ and $\mathrm{Fe}_{2} \mathrm{O}_{3}$. In most cases, iron oxides interpenetrate to form layers with complex compositions and structures, so scale varies even on different areas of the same specimen, which complicates metal pickling considerably.

Scale removal is a complex process that involves both chemical and electrochemical mechanisms. According to A. S. Afanas'ev [3-5], the scale removal process can be divided into four periods: 
1. Soaking of scale with an acid involving insignificant dissolution of oxides and the metal on the bottom of pores and cracks existing in the scale.

2. Further soaking of scale with the acid involving fast chemical and electrochemical dissolution of metal oxides.

3. Fast electrochemical dissolution of scale under the effect of the metal-scale galvanic couple. During this period, hydrogen evolution starts, which loosens and breaks the scale. Up to $70 \%$ of scale is removed during this period.

4. Electrochemical dissolution of the remaining scale and delamination of $\mathrm{Fe}_{3} \mathrm{O}_{4}$, a hardly soluble scale component. Removal of the remaining scale (25-30\%) occurs, which is accompanied by intense metal corrosion $(2-4 \%$ of the steel mass is lost unless metal corrosion inhibitors are used [6]).

The dynamics of this process is visualized by the scheme suggested by N. I. Podobaev for a two-component scale (Fig. 1) [7]. The scale removal in sulfuric acid mostly involves metal undercut etching and scale loosening by the evolving hydrogen [6].

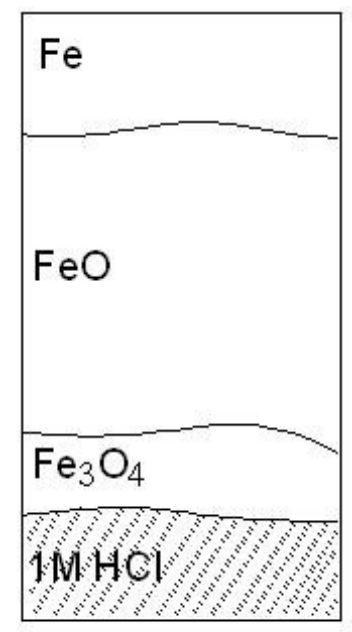

Initial state

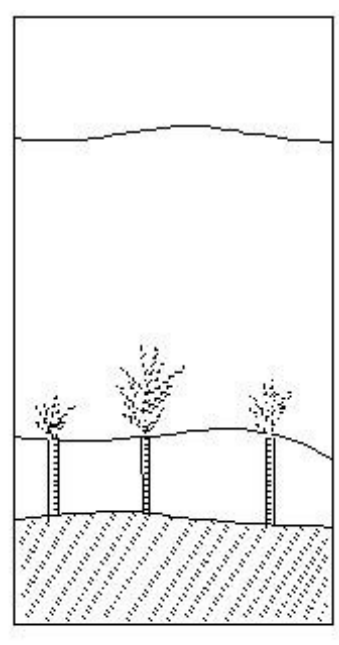

I

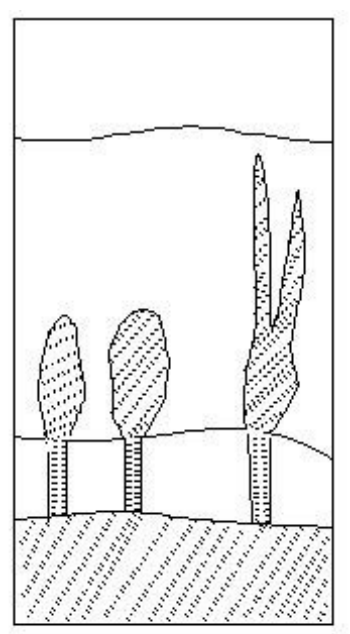

Period of pickling

II

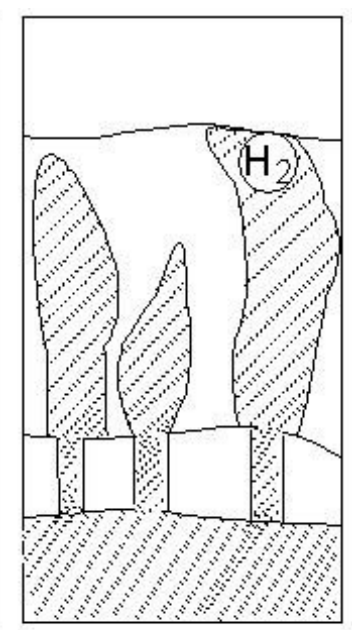

III

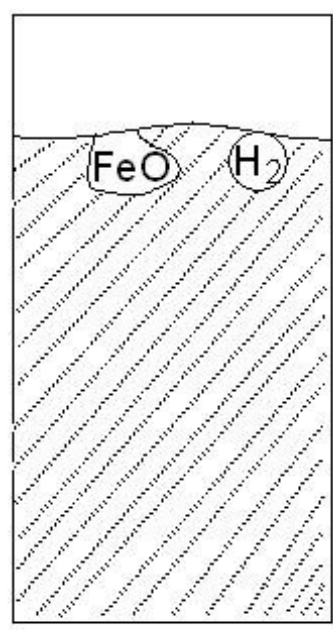

IV

Fig. 1. Scheme of pickling dynamics of wustite-magnetite scale on steel 10 in $1 \mathrm{M} \mathrm{HCl}$.

The use of acid corrosion inhibitors during steel pickling makes it possible to decrease the metal losses considerably; however, the inhibitors should not slow down the scale removal, otherwise the pickling time would increase significantly. These requirements were met by many inhibitors produced in the USSR (PHU, KPI-3, S-5U, KhOSP-10P) [8].

The search for highly efficient inhibitors of acid corrosion resulted in the creation of a new class of such inhibitors based on triazole derivatives: IFKhAN-92, IFKhAN-93, and IFKhAN-94 [9, 10]. In particular, IFKhAN-92 is efficient against corrosion of low carbon steel in sulfuric acid solutions in a broad temperature range $\left(0-140^{\circ} \mathrm{C}\right)$ [11]. Furthermore, 
it decreases hydrogen absorption by steel [12] and is resistant against $\mathrm{Fe}$ (II) and $\mathrm{Fe}$ (III) cations [13].

A considerable number of techniques exist for studying the dissolution rate of iron oxide phases in solutions of mineral acids [14]; however, most of them are unsuitable for studying the complex "scale - steel" system. We used the potentiometric method to estimate the rate of scale removal from the steel surface. It is known that the electrode potential $(E)$ of steel covered by scale in acid solutions amounts to $0.2-0.5 \mathrm{~V}$, whereas the $E$ of the active metal under the same conditions has negative values. Thus, the jump of the electrode potential on the potential - time curve characterizes the time for scale removal.

The purpose of this work was to study the effect of triazole derivatives (IFKhAN-92) on the scale removal from low carbon steel. In order to estimate the efficiency of the inhibitor in question, we also studied Catamin $\mathrm{AB}$, a commercial inhibitor.

\section{Experimental}

The corrosion rate of low carbon steel St3 in $2 \mathrm{M} \mathrm{H}_{2} \mathrm{SO}_{4}$ was determined from the mass loss of specimens (at least three specimens per point) with dimensions of $50.0 \mathrm{~mm} \times$ $20.0 \mathrm{~mm} \times 1.5 \mathrm{~mm}$, using $50 \mathrm{ml}$ of the acid solution per specimen. Prior to the experiments, the specimens were cleaned on an abrasive disc (ISO 9001, 60 grit) and degreased with acetone. The test duration was $2 \mathrm{~h}$.

The properties of scale-covered steel were studied on cylindrical St3 specimens $3.5 \mathrm{~mm}$ in diameter and $40 \mathrm{~mm}$ in length. The scale was created by placing the specimens for $8 \mathrm{~min}$ into a closed electric furnace at $950^{\circ} \mathrm{C}$ followed by cooling in the air. The resulting mean scale content on the steel surface was $162 \mathrm{~g} / \mathrm{m}^{2}$. After cooling, specimens with visual defects of the scale layer were discarded. The specimen end surfaces were insulated with epoxy resin. At least ten measurements per point were made in order to obtain reliable results.

The time for scale removal in $2 \mathrm{M} \mathrm{H}_{2} \mathrm{SO}_{4}$ was determined potentiometrically from variation of $E$ versus time using an EL-02.061 potentiostat. The working electrode potentials were measured against a silver - silver chloride electrode and converted to the normal hydrogen scale. The experimental data thus obtained were processed by calculating the mean time for scale removal and the confidence interval (at confidence level 0.95).

Voltammetric measurements were carried out using an IPC-Pro potentiostat from $E=-0.50 \mathrm{~V}$ to $E=0.60 \mathrm{~V}$ on scale-covered steel, in $0.2 \mathrm{M} \mathrm{H}_{2} \mathrm{SO}_{4}\left(25^{\circ} \mathrm{C}\right)$, by recording polarization curves in the positive direction at a potentiodynamic sweep rate of $0.010 \mathrm{~V} / \mathrm{s}$. Polaization curves were recorded one by one, each $2.5 \mathrm{~min}$ after the experiment was started.

The coulometric study of the scale removal process was carried out on scale-covered steel specimens, in $2 \mathrm{M} \mathrm{H}_{2} \mathrm{SO}_{4}\left(25^{\circ}\right)$, at $E=0.00 \mathrm{~V}$, using an IPC-Pro potentiostat and a three-electrode cell. 
Due to the low solubility of IFKhAN-92, it was added to the acid solution as a solution in ethanol. The resulting ethanol concentration in the pickling solution was 0.24 $\mathrm{mol} / \mathrm{l}$. The efficiency of the inhibitors was estimated from the inhibition coefficient, $\gamma=k_{0} / k_{\text {in }}$, and the degree of protection $Z=\left[\left(k_{0}-k_{\text {in }}\right) / k_{0}\right] \cdot 100 \%$ where $k_{0}$ and $k_{\text {in }}$ are the corrosion rates in the non-inhibited solution and in the solution with the compound being studied, respectively.

Solutions were prepared from sulfuric acid ("chemically pure" grade) and distilled water. The concentrations of the inhibitors (IFKhAN-92, Catamin AB) were $C_{\text {in }}=5.0 \mathrm{mM}$ for separate inhibitors or $C_{\text {in }}=2.5 \mathrm{mM}$ in mixtures. The content of additives ( $\mathrm{KI}, \mathrm{KBr}$, KCNS) in mixtures with nitrogen-containing inhibitors was $C_{\text {add }}=2.5 \mathrm{mM}$.

\section{Results and Discussion}

\section{Effect of inhibitors on the corrosion of low carbon steel}

The corrosion rate of St3 steel in $2 \mathrm{M} \mathrm{H}_{2} \mathrm{SO}_{4}$ increases regularly with an increase in $t$ (Table 1). The rate of the process increases 60 -fold upon a temperature increase from 25 to $95^{\circ} \mathrm{C}$. The presence of $5 \mathrm{mM}$ Catamin $\mathrm{AB}$ inhibits corrosion considerably and provides $\mathrm{Z}>$ $90 \%$ in the entire temperature range studied. An increase in $t$ by $70^{\circ} \mathrm{C}$ increases the $\gamma$ of Catamin AB 6.0-fold.

Table 1. Corrosion inhibition factors of St3 by IFKhAN-92 and Catamin AB (5.0 mM) in $2 \mathrm{M} \mathrm{H}_{2} \mathrm{SO}_{4}$

\begin{tabular}{cccc}
\hline \multirow{2}{*}{,${ }^{\circ} \mathbf{C}$} & $\begin{array}{c}\text { Corrosion rate in non-inhibited } \\
\text { solution, } \boldsymbol{k}_{\mathbf{0}}, \mathbf{g} /\left(\mathbf{m}^{\mathbf{2}} \cdot \mathbf{h}\right)\end{array}$ & \multicolumn{2}{c}{ Inhibition factor, $\boldsymbol{\gamma}$} \\
\cline { 3 - 4 } & 1033 & IFKhAN-92 & Catamin AB \\
\hline 95 & 366 & 271 & 62.8 \\
80 & 117 & 212 & 55.5 \\
60 & 44.9 & 142 & 33.1 \\
40 & 17.2 & 64.2 & 22.0 \\
25 & 26.9 & 10.5 \\
\hline
\end{tabular}

IFKhAN-92 proved to be a more efficient inhibitor than Catamin AB. The $\gamma$ values observed for IFKhAN-92 are 2.8-4.3 times higher than those for Catamin AB. The $\gamma$ value of IFKhAN-92 increases 10-fold with a temperature increase from 25 to $95^{\circ} \mathrm{C}$.

Mixtures of nitrogen-containing inhibitors containing anions that are more hydrophobic than the anions of the corrosive medium $\left(\mathrm{HSO}_{4}^{-}, \mathrm{SO}_{4}^{2-}\right)$ are either superior to separate inhibitors in protective effect or similar to them in terms of $\gamma$ (Fig. 2). The highest $\gamma$ values are observed for mixtures containing IFKhAN-92. Of the additives studied, the best result is provided by $\mathrm{KI}$. 


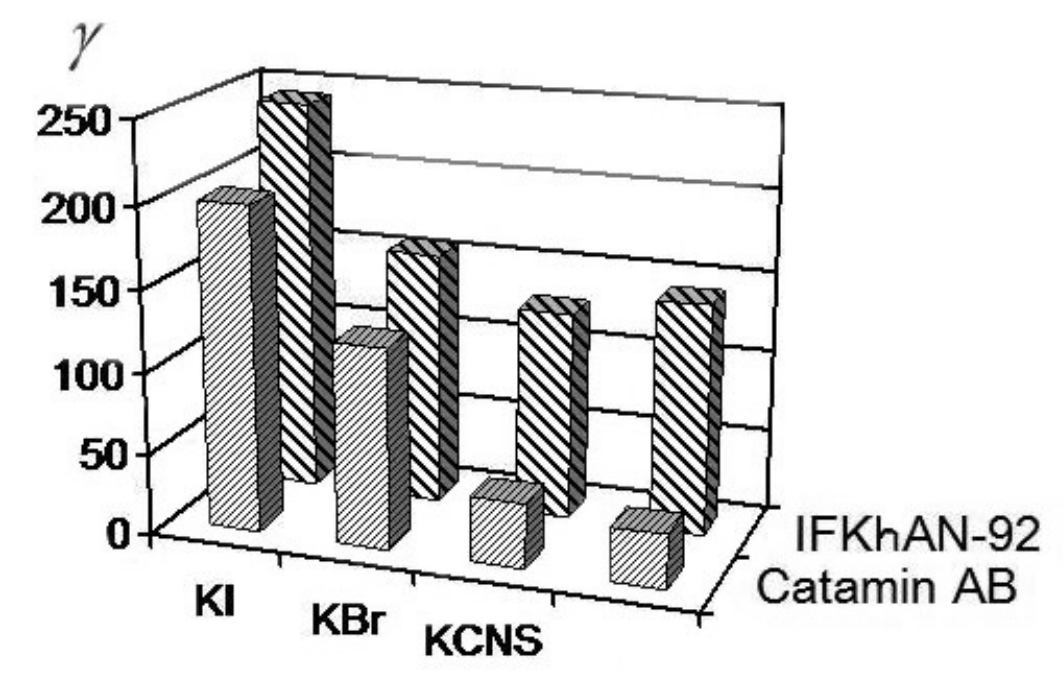

Fig. 2. Corrosion inhibition factors of St 3 in $2 \mathrm{M} \mathrm{H}_{2} \mathrm{SO}_{4}$ by nitrogen-containing inhibitors and their equimolar mixtures with relatively anions at $60^{\circ} \mathrm{C}$.

Thus, both inhibitors studied and the mixtures based on them show high efficiency against steel corrosion in sulfuric acid. In terms of this criterion, they meet the requirements for industrial inhibitors of acid corrosion. However, the $\gamma$ values in solutions containing IFKhAN-92 are considerably higher than those for Catamin AB.

\section{Effect of inhibitors on scale removal from low carbon steel surface}

In the reference solution $\left(2 \mathrm{M} \mathrm{H}_{2} \mathrm{SO}_{4}\right)$, the potential of scale-covered steel is positive during an initial period ( $E>0.4 \mathrm{~V}$ ) (Fig. 3). During this period, the electrode potential first slightly increases and then starts to decrease more slowly. This is accompanied by scale removal from the steel surface; the completion of this process is characterized by an abrupt decrease in the electrode potential to negative values $(E<0.0 \mathrm{~V})$. After that, some steadystate negative electrode potential is established, which corresponds to the corrosion potential of steel in the acid solution. Based on the potentiometric curves obtained for the scale-covered steel electrode, the time for scale removal was determined from the potential drop from the positive to the negative region (Table 2). One can see that the time for scale removal increases considerably with a decrease in temperature. A decrease by $70^{\circ} \mathrm{C}$ makes the scale removal 15.9 times slower.

The presence of IFKhAN-92 or Catamin AB in the solution does not slow down the scale removal (Table 2). Similarly to the reference solution, the scale removal slows down with a decrease in temperature.

A calculation of the activation energy for scale removal by the Arrhenius equation shows (Fig. 4) that it amounts to $37 \pm 3 \mathrm{~kJ} / \mathrm{mol}$ and does not depend on whether an inhibitor is present in solution. This value suggests that the process occurs under mixed diffusion kinetic control. 


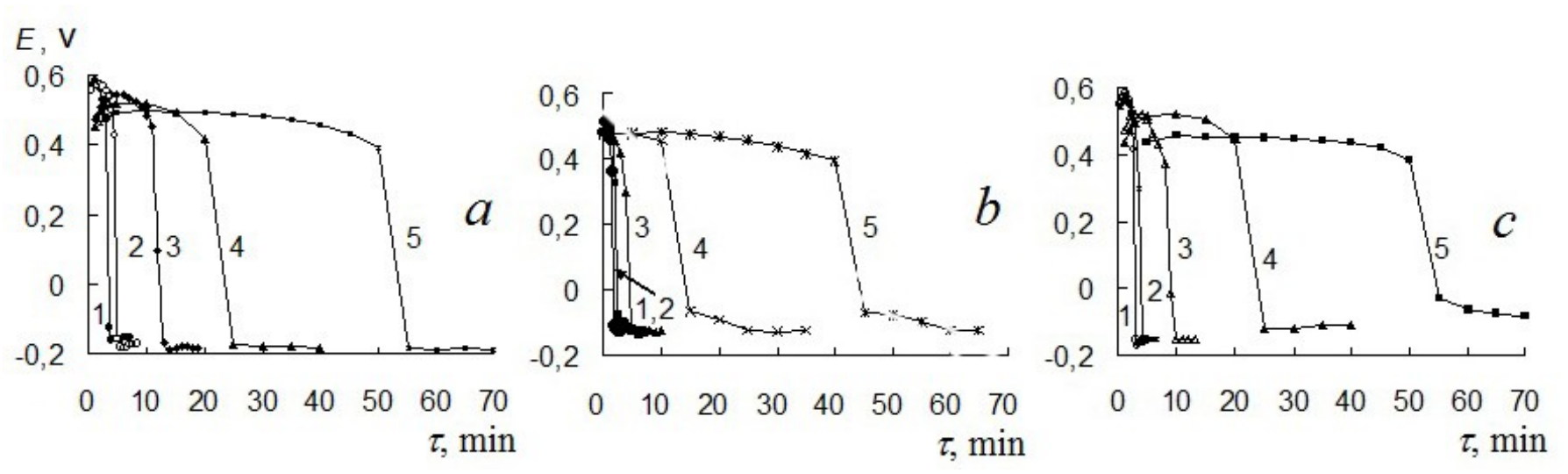

Fig. 3. Plots of potential of scale-covered St3 specimens versus time of pickling in $2 \mathrm{M} \mathrm{H}_{2} \mathrm{SO}_{4}$ (a) containing $5 \mathrm{mM}$ IFKhAN-92 $(b)$ or $5 \mathrm{mM}$ Catamin $\mathrm{AB}(c)$ at temperatures $\left({ }^{\circ} \mathrm{C}\right): 1-95$, $2-80,3-60,4-40,5-25$.

Table 2. Time for scale removal (min) from St3 specimens in $2 \mathrm{M} \mathrm{H}_{2} \mathrm{SO}_{4}$ inhibited by nitrogen-containing compounds $(5.0 \mathrm{mM})$.

\begin{tabular}{cccc}
\hline $\boldsymbol{t},{ }^{\circ} \mathbf{C}$ & \multicolumn{3}{c}{ Inhibitor } \\
\cline { 2 - 4 } & - & Catamin AB & IFKhAN-92 \\
\hline 95 & $3 \pm 2$ & $3 \pm 1$ & $2 \pm 1$ \\
80 & $6 \pm 1$ & $5 \pm 2$ & $3 \pm 1$ \\
60 & $12 \pm 3$ & $8 \pm 2$ & $7 \pm 1$ \\
40 & $25 \pm 5$ & $23 \pm 4$ & $18 \pm 3$ \\
25 & $54 \pm 16$ & $51 \pm 14$ & $48 \pm 10$ \\
\hline
\end{tabular}

Similarly, the scale removal is not hindered by mixtures of nitrogen-containing inhibitors with anionic additives (KI, KBr, or KCNS) (Table 3).

Table 3. Time for scale removal (min) from St3 specimens in $2 \mathrm{M} \mathrm{H}_{2} \mathrm{SO}_{4}\left(60^{\circ} \mathrm{C}\right)$ inhibited by equimolar mixtures of nitrogen-containing compounds and anionic additives. $\mathrm{C}_{\mathrm{mix}}=5 \mathrm{mM}$.

\begin{tabular}{cccc}
\hline Inhibitor & & Additive & \\
\cline { 2 - 4 } & KI & KBr & KCNS \\
\hline Catamin AB & $7 \pm 2$ & $8 \pm 3$ & $9 \pm 3$ \\
IFKhAN-92 & $7 \pm 1$ & $9 \pm 3$ & $7 \pm 2$ \\
\hline
\end{tabular}




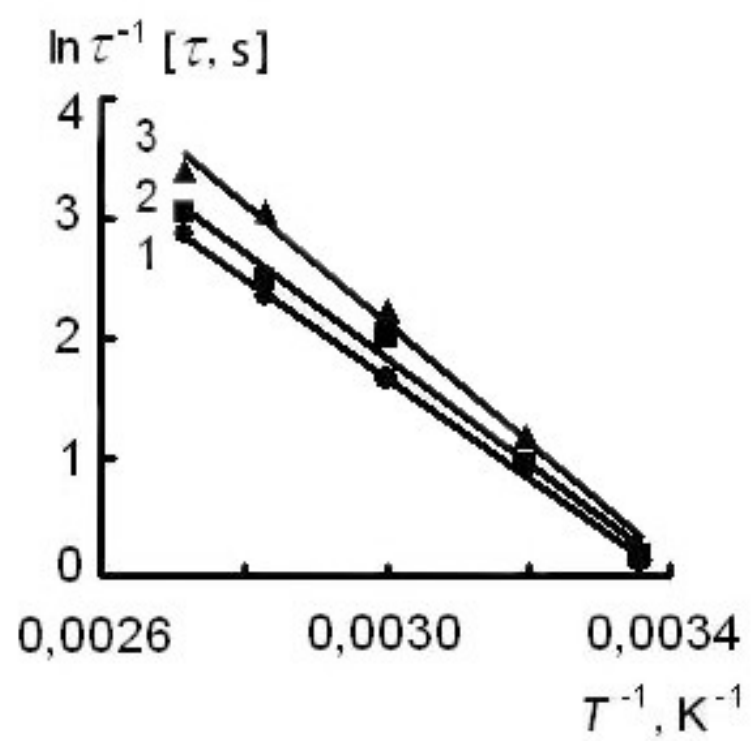

Fig. 4. Plot of $\ln \tau^{-1}$ versus $T^{-1}$ for scale removal from $\mathrm{St} 3$ surface in $2 \mathrm{M} \mathrm{H}_{2} \mathrm{SO}_{4}$ (1) containing $5 \mathrm{mM}$ Catamin AB (2) or $5 \mathrm{mM}$ IFKhAN-92 (3).

The results obtained allow us to compare the two inhibitors, Catamin AB and IFKhAN-92. Both inhibitors and mixtures on their basis do not slow down the scale removal. However, IFKhAN-92 and its mixtures with anionic additives inhibit steel corrosion much more efficiently. It can thus be concluded that IFKhAN-92 is more promising than Catamin AB for industrial pickling of low carbon steel aimed at scale removal.

Our potentiometric studies allow only the time for scale removal to be estimated but do not provide any information concerning the chemistry and kinetics of scale pickling. Additional data about processes that occur with scale in an acid solution can be provided by voltammetric and coulometric measurements.

Analysis of polarization curves of scale-covered steel in $0.2 \mathrm{M} \mathrm{H}_{2} \mathrm{SO}_{4}$ recorded in a sequential manner (Fig. $5 a$ ) showed that they contained a magnetite cathodic reduction peak at $E=0.25 \mathrm{~V}$. In the reference solution, the cathodic current increases due to scale pickling for the first ten minutes. After that, the magnetite reduction current decreases, which suggests that the fraction of its phase decreases. The cathodic current of magnetite reduction is still observed after 20 min from the start of scale pickling. 

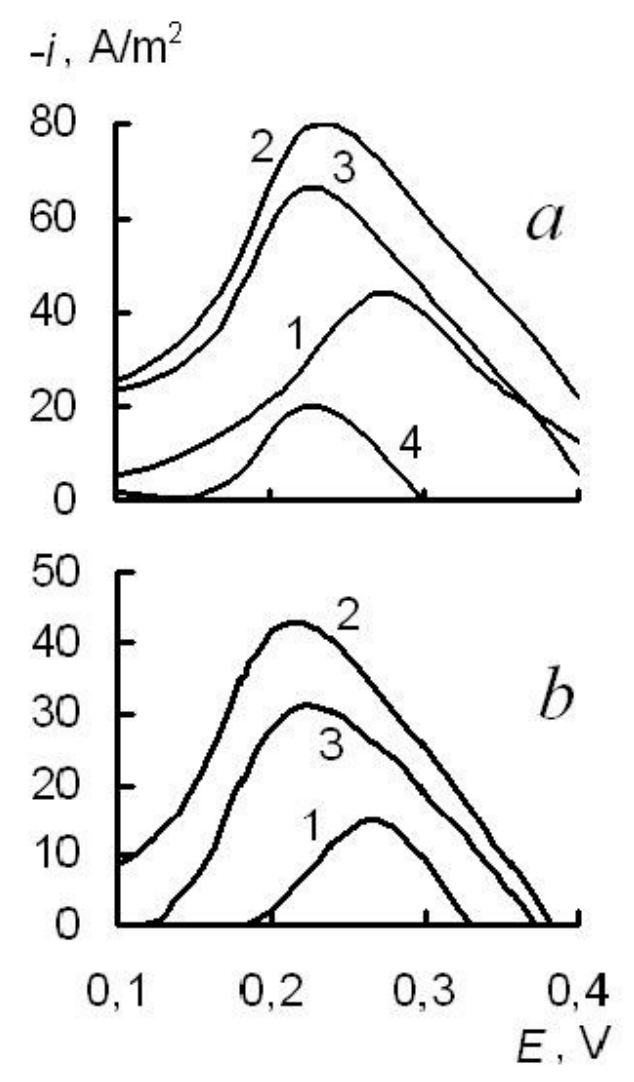

Fig. 5. Polarization curves of scale-covered St3 steel in $0.2 \mathrm{M} \mathrm{H}_{2} \mathrm{SO}_{4}(a)$ containing $5 \mathrm{mM}$ IFKhAN-92 (b) with exposures (min): $1-0,2-10,3-15,4-20 . t=25^{\circ} \mathrm{C}$.

The presence of IFKhAN-92 decreases the current of magnetite cathodic reduction (Fig. $5 b$ ). Like in the non-inhibited solution, the magnetite reduction current increases for $10 \mathrm{~min}$ and then decreases. It is important to note that after $20 \mathrm{~min}$ of scale pickling in the acid inhibited with IFKhAN-92, no magnetite reduction current is observed, which indicates that it is not present in the scale. The pattern of magnetite cathodic reduction in a solution containing Catamin $\mathrm{AB}$ is qualitatively similar to that in the solutions with IFKhAN-92. Hence, although IFKhAN-92 and Catamin AB slow down the cathodic reduction of magnetite, they do not prevent its removal during scale pickling.

In order to identify the specific features of the kinetics of scale removal from steel, we performed a coulometric study of this process at $E=0.00 \mathrm{~V}$, where the rate of scale cathodic reduction is rather slow. The plots of cathodic current density for scale reduction versus time have a parabolic shape (Fig. 6). 


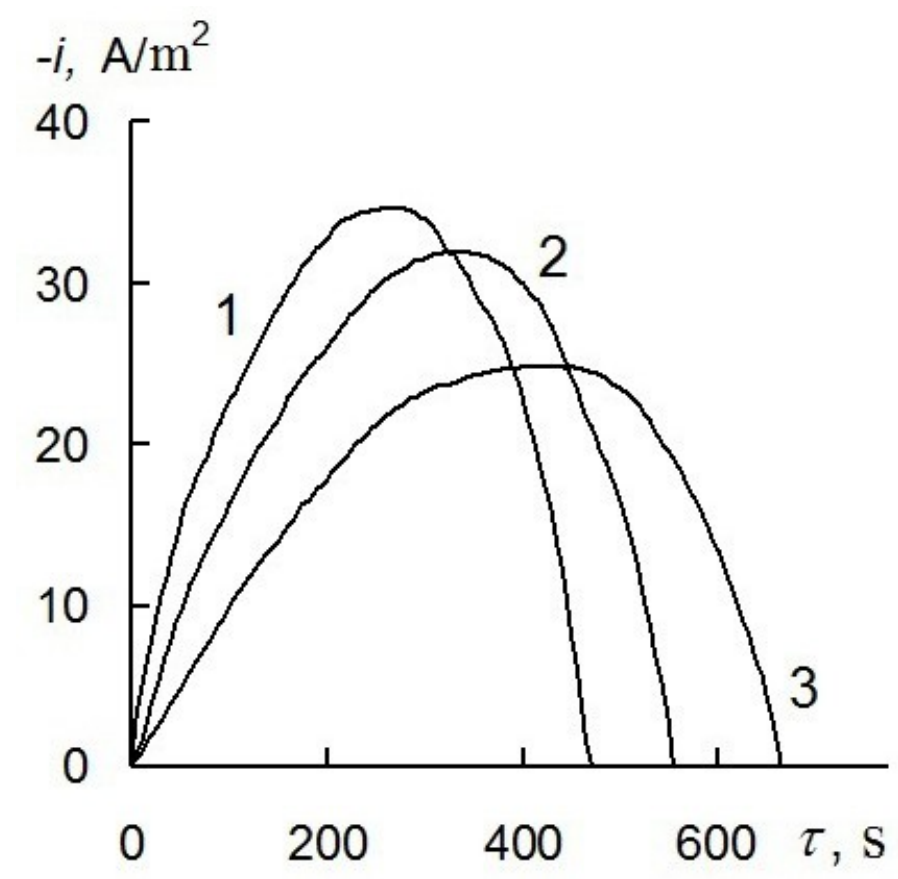

Fig. 6. Plot of cathodic current density for scale reduction $(E=0.00 \mathrm{~V})$ versus time in $2 \mathrm{M}$ $\mathrm{H}_{2} \mathrm{SO}_{4}(1)$ containing $5 \mathrm{mM}$ Catamin AB (2) or $5 \mathrm{mM}$ IFKhAN92 (3), $t=25^{\circ} \mathrm{C}$.

In order to calculate the quantity of charge consumed for scale reduction, the coulometric curves were described by a polynomial of the form:

$$
i=a+b \tau+c \tau^{2}
$$

where $i$ is the cathodic current density; $\tau$ is time; $a, b$ and $c$ are constants of the square polynomial. The total quantity of charge is determined by the equation:

$$
Q=\int_{0}^{\tau}\left(a+b \tau+c \tau^{2}\right) d \tau,
$$

while the degree of conversion $\alpha$ is described by the equation:

$$
\alpha=\frac{Q_{\tau}}{Q_{\max }}
$$

where $Q_{\tau}$ is the quantity of charge consumed for scale reduction by time $\tau$ and $Q_{\max }$ is the quantity of charge consumed for the complete reduction of scale. The plots of the fraction of dissolved scale versus time (Fig. 7) are well described by Erofeev's equation [14]:

$$
\alpha=1-\exp \left(-(W \tau)^{n}\right) \text {, }
$$

where $W$ is the pickling rate constant and $n$ is the fractal dimensionality of the dissolving phase. Analysis of the data presented in Fig. 7 allows $W$ and $n$ to be calculated (Table 4). 
The presence of the nitrogen-containing inhibitors of interest in the sulfuric acid solution does not change the fractal dimensionality of the dissolving oxide phase. The value of the constant, $n=2.3$, indicates that cathodic reduction of scale occurs not only on the surface but also involves deeper layers (roughness). The $W$ values decrease somewhat in the presence of inhibitors, which suggests that they inhibit somewhat the scale cathodic reduction.

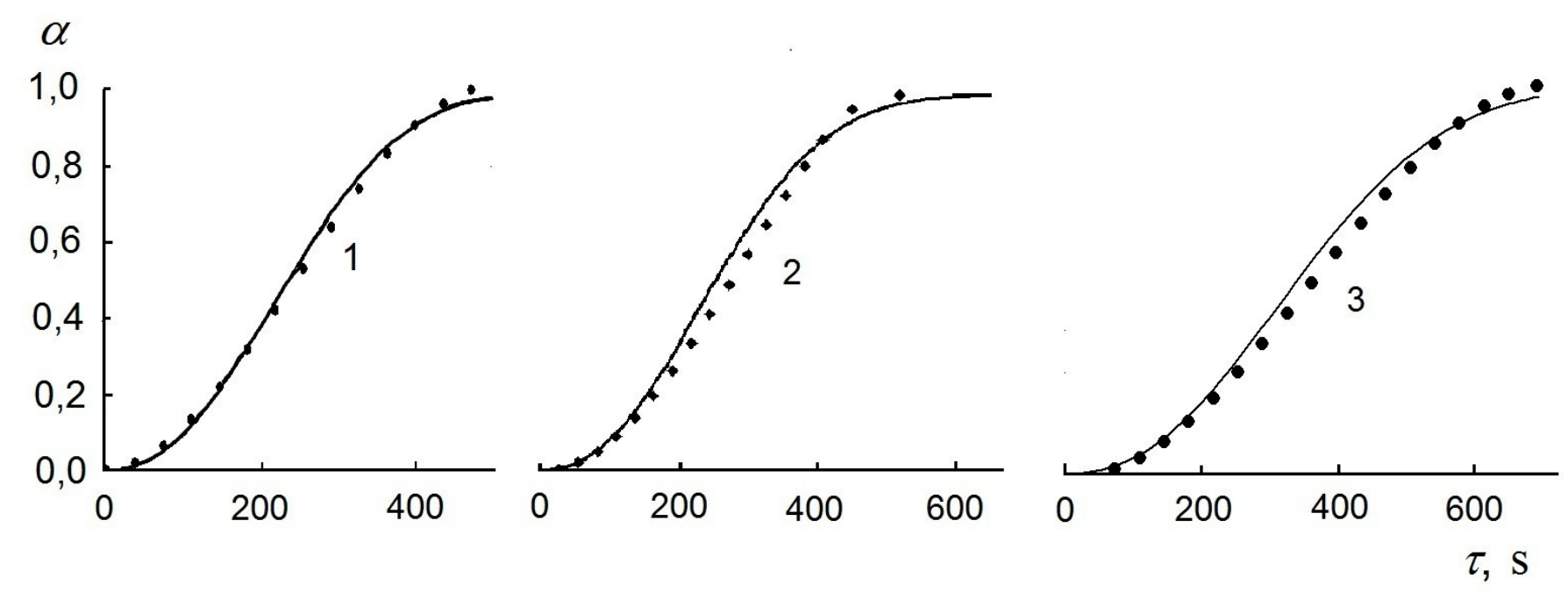

Fig. 7. Plot of scale degree of conversion versus time during cathodic reduction $(E=0.00 \mathrm{~V})$ in $2 \mathrm{M} \mathrm{H}_{2} \mathrm{SO}_{4}$ (1) containing $5 \mathrm{mM}$ Catamin $\mathrm{AB}$ (2) or $5 \mathrm{mM}$ IFKhAN92 (3). The dots show experimental data and the solid line shows the results of simulation using Erofeev's equation.

Table 4. Kinetic parameters of Erofeev's equation for the cathodic reduction of scale in $2 \mathrm{M} \mathrm{H}_{2} \mathrm{SO}_{4}$ $\left(25^{\circ} \mathrm{C}\right)$ at $E=0.00 \mathrm{~V}$.

Constant

\begin{tabular}{cccc}
\cline { 2 - 4 } & - & $\mathbf{5} \mathbf{~ m M}$ Catamin AB & $\mathbf{5}$ mM IFKhAN-92 \\
\hline$W, \mathrm{~s}^{-1}$ & 0.0036 & 0.0034 & 0.0025 \\
$n$ & 2.3 & 2.3 & 2.3 \\
\hline
\end{tabular}

It is important to note that the inhibition of scale cathodic reduction by the inhibitors identified by electrochemical methods does not considerably affect the process of scale removal from the metal surface, since scale pickling occurs at $E>0.4 \mathrm{~V}$, whereas the reduction process is possible at $E<0.4 \mathrm{~V}$. This conclusion agrees with potentiometric data showing that the inhibitors do not affect scale removal as a whole. 


\section{Conclusions}

1. A comprehensive approach to the assessment of the inhibitor effect on steel acid pickling has been implemented, in which not only the factor of slowing down the metal pickling rate was estimated but also the scale removal process was studied.

2. Scale pickling in non-inhibited sulfuric acid solutions and in those inhibited with IFKhAN-92 or Catamin AB occurs under mixed diffusion and kinetic control.

3. Both inhibitors studied do not slow down scale pickling in sulfuric acid solutions, while IFKhAN-92, both separately and in mixtures containing relatively hydrophobic anions, inhibits the corrosion of steel much better than Catamin AB.

4. A coulometric study of the electrochemical component of scale pickling has shown that this process is well described by Erofeev's equation for heterogeneous kinetics. The kinetic parameters of Erofeev's equation have been calculated for the process studied.

\section{References}

1. L. I. Antropov, E. M. Makushin and V. F. Panasenko, Ingibitory korrozii metallov (Metal Corrosion Inhibitors), Tehnika, Kiev, 1981, 58 (in Russian).

2. N. D. Tomashov, Teoriya korrosii $i$ zashchity metallov (Theory of corrosion and protection of metals), AN SSSR, Moscow, 1960, 74 (in Russian).

3. A. S. Afanas'ev and L.A. Belyaev, in Travlenie i obezzhirivanie trub iz stalei i splavov (Pickling and degreasing of pipes made of steels and alloys), Metallurgiya, Moscow, 1967, 55 (in Russian).

4. A. S. Afanas'ev and T. B. Malyisheva, in Travlenie $i$ obezzhirivanie trub iz stalei $i$ splavov (Pickling and degreasing of pipes made of steels and alloys), Metallurgiya, Moscow, 1967, 59 (in Russian).

5. A. S. Afanas'ev and G. M. Khvedchenyan, in Travlenie i obezzhirivanie trub iz stalei $i$ splavov (Pickling and degreasing of pipes made of steels and alloys), Metallurgiya, Moscow, 1967, 51 (in Russian).

6. D. Bartl and O. Mudrox, Tekhnologiya khimicheskoi i elektrokhimicheskoi obrabotki stali (The technology of chemical and electrochemical treatment of steel), Mashgiz, Moscow, 1961 (in Russian).

7. N. I. Podobaev and N. M. Shcheglov, in Uchenyie zapiski (Scientific notes), eds. S. A. Balezin, V. S. Polosin, N. I. Podobaev, E. G. Zak and L. F. Gorin, MGPI im V. I. Lenina, Moscow, 1971, 340, 184 (in Russian).

8. S. M. Reshetnikov, Ingibitory kislotnoi korrozii metallov (Metal Corrosion Inhibitors in Acids), Khimiya, Leningrad, 1986, 122-134 (in Russian).

9. Ya. G. Avdeev, P. A. Belinsky, Yu. I. Kuznetsov and O. O. Zel', Korroziya: materialy, zaschita, 2008, no. 8, 16.

10. Ya. G. Avdeev, Yu. I. Kuznetsov and O. O. Zel', Korroziya: materialy, zaschita, 2010, no. $7,12$. 
11. Ya. G. Avdeev, P. A. Belinsky, Yu. I. Kuznetsov and O. O. Zel', Korroziya: materialy, zaschita, 2010, no. 1, 27.

12. Ya. G. Avdeev, L. V. Frolova, Yu. I. Kuznetsov and O. O. Zel', Korroziya: materialy, zaschita, 2010, no. 5, 22.

13. Ya. G. Avdeev, P. A. Belinsky, Yu. I. Kuznetsov and O. O. Zel', Korroziya: materialy, zaschita, 2009, no. 1, 20.

14. I. G. Gorichev, A. M. Kutepov, A. I. Gorichev et al., Kinetika $i$ mekhanizm rastvoreniya oksidov $i$ gidroksidov zheleza $v$ kislykh sredakh (Kinetics and mechanism of dissolution of iron oxides and hydroxides in acidic media), RUDN, Moscow, 1999 (in Russian). 